\title{
Development and Evaluation of an Educational Program for Community Pharmacists on Cardiovascular Risk Assessment
}

This article was published in the following Dove Press journal: Risk Management and Healthcare Policy

\author{
Monica Zolezzi (1) \\ Oraib Abdallah ${ }^{2}$ \\ Sowndramalingam \\ Sankaralingam (iD) \\ 'Department of Clinical Pharmacy and \\ Practice, College of Pharmacy, Qatar \\ University, Doha, Qatar; ${ }^{2}$ Hamad Medical \\ Corporation, Doha, Qatar
}

Purpose: Cardiovascular disease (CVD) risk assessment is an important strategy for the prevention of CVD. Pharmacists play an important role in CVD risk assessment and management (CVDRAM). Our previous study identified gaps in knowledge among community pharmacists for the provision of CVDRAM services as assessed through patient simulation. Therefore, our objectives were: a) to develop and evaluate an educational program on CVD risk assessment for community pharmacists, b) to assess the knowledge and skills of participating pharmacists in assessing and managing CVD risk before and after enrolling in the educational program and c) to explore pharmacists' satisfaction and perceived effectiveness of the educational program.

Methods: Using a blended learning instructional approach, the educational program for a subset of 25 community pharmacists recruited from our previous study consisted of two face-to-face workshops, and an online 5-module course on CVD risk factors such as hyperlipidemia, hypertension, diabetes, obesity, and smoking cessation based on principles of adult learning. A repeated measures study design was utilized by measuring participants' knowledge on pre- and post-questionnaires and an objective structured clinical examination (OSCE) at the conclusion of the educational program was also used to assess its impact on the knowledge and skills of community pharmacists in the provision of CVD risk assessment and management (CVDRAM) services. The knowledge questionnaire was completed by 23 pharmacists while the OSCE was completed by 8 pharmacists. In addition, a survey assessed the pharmacists' level of satisfaction with the educational program.

Results: At the conclusion of the educational program, the participating pharmacists achieved knowledge and skills for the provision of CVDRAM services. Knowledge scores in relation to CVDRAM significantly improved after the educational program [out of a maximum of 20 points, the median (interquartile range) $=9(7-9)$ at pre- vs 12 (12-13) at post-educational program], $\mathrm{p}<0.001$. On the OSCE, the median (interquartile range) scores for Stations 1 and 2 were 66 (63-71) and 71 (67-76), respectively. Out of the 21 pharmacists that completed the satisfaction survey, $71 \%$ were very satisfied and $29 \%$ were satisfied with the educational program.

Conclusion: The educational program improved pharmacists' knowledge and skills for the provision of CVDRAM services.

Keywords: community pharmacists, cardiovascular disease risk assessment, educational program, pharmacists' preparedness, evaluation

\section{Introduction}

Cardiovascular disease (CVD) is the most common cause of death globally. ${ }^{1}$ In Qatar, CVD was responsible for $24 \%$ of the total deaths reported in $2013 .{ }^{2,3}$ Furthermore, reports from the World Health Organization (WHO) have indicated high prevalence
Sankaralingam

Dractice

University, Building I 06, 2nd Floor, Room

S A2.06, Doha, Qatar

Tel +97444035618

Fax +9744403555 I

Email sownd@qu.edu.qa 
rates of CVD risk factors in Qatar, such as tobacco smoking, hypertension, obesity, dyslipidemia and diabetes. ${ }^{2,4,5}$ Despite considerable evidence-based knowledge about risk factor management, CVD remains the leading cause of disability and premature death throughout the world. ${ }^{4}$ Consequently, WHO recommends prevention ${ }^{2,3}$ of CVD through early detection and management of individuals who are at a high risk of developing CVDs. ${ }^{1}$ This necessitates the need for development and implementation of highly accessible screening programs to assess and manage cardiovascular risk. A precise estimate of the absolute risk for developing a first CVD event using tools such as the Framingham Risk Score is preferred when making prevention and treatment recommendations. ${ }^{4,5}$

Community pharmacists are one of the most accessible healthcare professionals that have been shown to play an effective role in screening and reducing the severity of established risk factors, as well as in the primary prevention and management of CVD. ${ }^{6-9}$ There is sufficient evidence for improved clinical outcomes when pharmacists are involved in the assessment of cardiovascular risk as outlined below. A recent large multi-centered controlled trial involving 56 community pharmacies in Canada that enrolled 723 patients has shown a $21 \%$ reduction in risk for CVD events after 3 months among patients that were under the care of pharmacists with competence in providing CVD risk assessment and management (CVDRAM) services compared to pharmacists providing usual care. ${ }^{10}$ A pilot study of 12 pharmacists in Australia that provided care for 67 participants showed a significant $25 \%$ proportional risk reduction in overall CVD risk. ${ }^{11}$ A meta-analysis of 30 randomized controlled trials of pharmacist-directed care or -collaborative care resulted in significant improvements in systolic and diastolic blood pressure, total cholesterol, low-density lipoprotein cholesterol and reduction in smoking. ${ }^{12}$

Despite this evidence, pharmacists in Qatar appear to be largely under-utilized and poorly integrated into primary care teams. In a recent study in Qatar, community pharmacists perceived a lack of education as the top barrier in the provision of services which promote cardiovascular health. ${ }^{13}$ In another recent study in Qatar, researchers worked with standardized patients (SPs) to assess the knowledge and skills of community pharmacists in the provision of CVD risk assessment services. ${ }^{14}$ The results of the study indicated a gap in the pharmacists' competence for the provision of CVDRAM services.

Currently, community pharmacists in the State of Qatar are primarily involved in dispensing medications and providing counseling. The State of Qatar has prioritized health promotion as part of its National Health Strategy. Consequently, there are plans to introduce enhanced and advanced pharmacy services managed by community pharmacists. It is therefore important to assess their baseline knowledge and skills to provide further education to successfully implement such services. No studies to date have reported the development and evaluation of educational programs for capacity building on CVD risk assessment among practicing pharmacists. The aim of the current study is to 1) develop and implement a CVD risk assessment educational program for community pharmacists; 2) to objectively evaluate the impact of the educational program on the knowledge and skills of participating pharmacists and 3) to assess the participant's perception of the educational program. We believe that this is a novel approach in Qatar and the materials developed will be updated and used in the future to train a large cohort of community pharmacists to advance their skills and knowledge.

One of the long-term goals of this study is to implement the provision of $\mathrm{CV}$ risk assessment services by community pharmacists in Qatar to improve patients' outcomes. Pharmacist intervention through CV risk assessment has been shown to reduce absolute risk of developing $\mathrm{CV}$ events. ${ }^{10,11}$ Importantly, recent studies in the Middle East region have shown community pharmacist interventions to reduce overall Atherosclerotic Cardiovascular Disease or Framingham risk score ${ }^{15,16}$ suggesting feasibility of such models in Qatar. Our previous study has shown that community pharmacists in Qatar are willing to learn and provide CVDRAM services. ${ }^{14}$ Therefore, this educational program can prove to be useful for the implementation of such services in Qatar.

\section{Methods \\ Study Participants}

Fifty pharmacists working in various community pharmacies in urban areas in the State of Qatar, whose preparedness in the provision of CVDRAM had been assessed during an interaction with a trained SP in our previous study, ${ }^{14}$ were invited to participate in this CVDRAM educational program. Twenty-five pharmacists participated in our current educational program.

\section{Educational Program Development}

A team of two pharmacists and a physician from the College of Pharmacy designed this educational program. 
Several international guidelines were used to develop the content of this program, ${ }^{2,17-20}$ which was delivered in a blended format consisting of two face-to-face workshops that lasted $3 \mathrm{hrs}$ each, complemented by an online course developed using Articulate $360^{\circledR}$ software (Articulate Storyline 360,2018$).{ }^{21}$ Appendix 1 provides a detailed outline of the educational program.

In the first workshop, participants were introduced to the role of community pharmacists in CVD risk assessment. CVD risk factors such as hyperlipidemia, hypertension, diabetes, obesity, and smoking cessation and approaches to the provision of CVDRAM services in community pharmacies were briefly reviewed. Following the first workshop, participants were given access to the web-based course which consisted of 5 learning modules, one for each of the preventable CVD risk factors mentioned above. Recommendations for pharmacological and non-pharmacological management strategies, reference to guidelines and additional resources were also provided. The modules consisted of lectures that were recorded directly into PowerPoint and converted into a web-based course using the online platform provided by the course builder software Articulate $360^{\circledR}$. This software provides a slide-based presentation with audio, guided quizzes, and active hyperlinks. Prior to launching, the content was peerreviewed by experts in the field, and then circulated to two pharmacy students. Experts and students provided feedback (in the form of reflection notes) on content, format and overall impression of the course content. Their reflections were taken into considerations before launching the final version of the online course. The workshop, webbased learning modules and OSCE components were accredited by the Qatar Council for Healthcare Practitioners (QCHP) and participating pharmacists will receive continuous education $(\mathrm{CE})$ credits.

Box 1 describes the content of the final version of the online course which continued to be available to participants beyond the study completion. Figure 1 shows a screenshot of the web-based course.

The second face-to-face workshop was scheduled 1 month later, at which participants were introduced to the steps in the implementation of CVDRAM services, and provided them with the opportunity to have hands-on training on the use of screening tools and point-of-care (POC) devices appropriate for use in community pharmacies for assessing cardiovascular risk factors. In addition, participants were trained on physical examination skills necessary for CVD risk assessment such as measurement
Box I Content of the Final Version of the Online Course on CVDRAM

Workshop I: Introduction to cardiovascular risk assessment and management

Learning module I: Management of dyslipidemia

Learning module 2: Management of hypertension

Learning module 3: Glycemic control and vascular complications in type 2 diabetes

Learning module 4: Weight and obesity management

Learning module 5: Smoking cessation

Workshop 2: Implementation of cardiovascular risk assessment

services

of blood pressure, height, and weight. As recommended in the guidelines on which this educational program was based on ${ }^{2,17-20}$ primary health care professionals need to convey information to patients in a way that allows them to understand their cardiovascular risk and the potential effects of lifestyle or pharmacological interventions, to actively engage patients in shared decision-making. As such, during the second workshop, participants also had the opportunity to interact with SPs in order to enhance their communication skills necessary for the provision of CVDRAM services. The case scenarios on which the SPs were trained and the SPs participating in this workshop were the same as those utilized in our previous study. ${ }^{14}$ Video recordings of both workshops were also incorporated into the final version of the web-based course.

\section{Assessment}

An attempt was made to follow the Kirkpatrick's evaluation framework to assess the course outcomes. The Kirkpatrick's framework is a widely used evaluation model to assess the effectiveness of CPD training and learning, a systematic approach consisting of four levels of evaluation involving examination of a course on multiple levels using different data sources. ${ }^{22}$ This model has been applied by several other researchers when developing courses in pharmacy practice education. ${ }^{23-27}$ As such, the course used pre-/postquestionnaires, interactive quizzes through the online module, SPs, OSCE and a satisfaction survey in an attempt to assess all 4 levels of Kirkpatrick's evaluation framework.

\section{Assessment of Participants' Knowledge and Skills}

Pre- and post-knowledge questionnaires were used to evaluate the impact of the educational program on pharmacists' knowledge. A set of 13 multiple-choice questions and 7 true/false questions were developed based on the content covered in the 


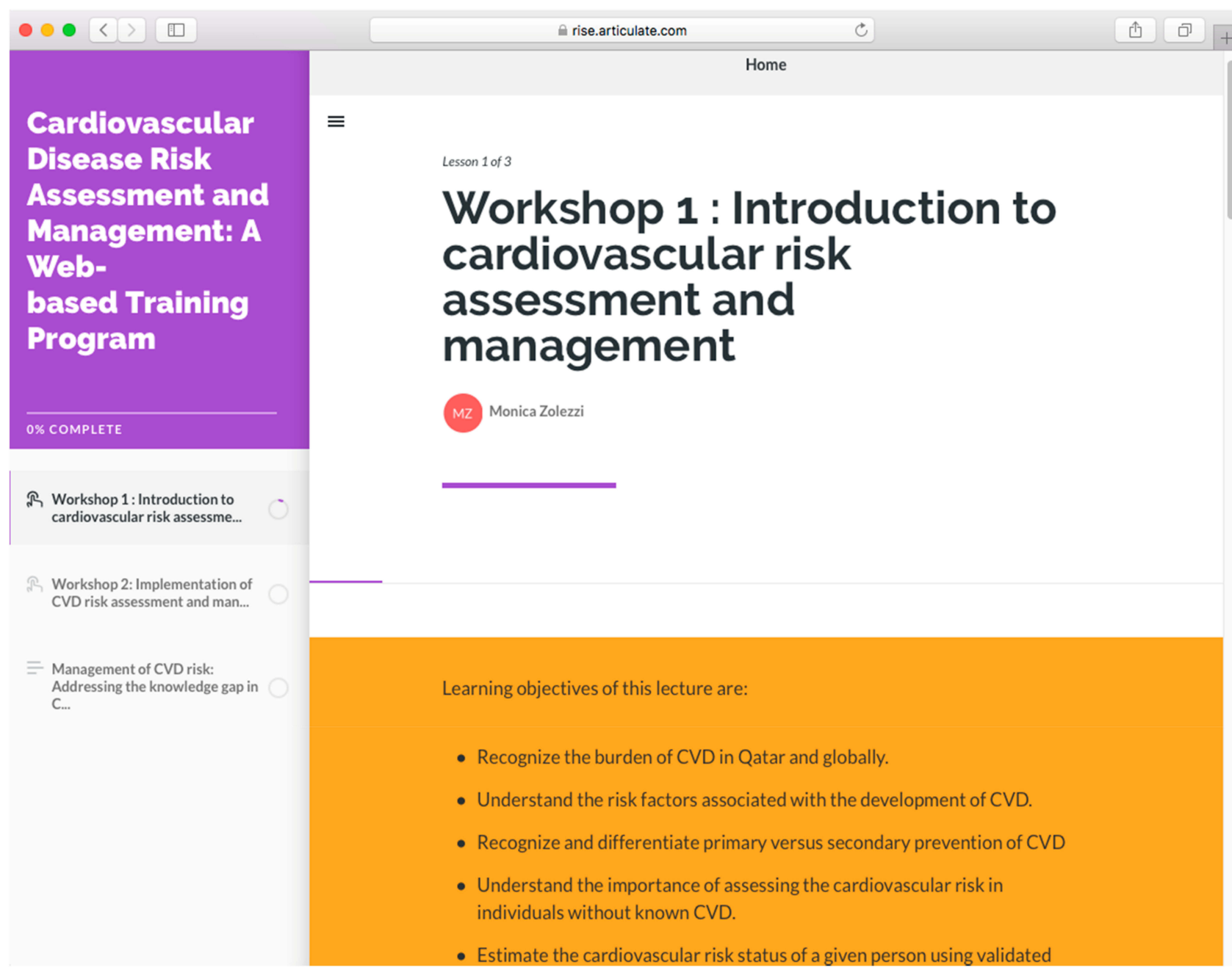

Figure I Screenshot of web-based course builder using Articulate $360^{\circledR}$ software. Representative screenshot of a course module developed using the Articulate $360^{\circledR}$ software is shown.

workshops and in the 5 learning modules. The pre- and postknowledge questionnaires used as part of the assessment process are provided as Appendix 2 and $\underline{3}$ respectively. The questions focused on knowledge related to risk factors necessary for estimating CVD risk, and on management guidelines including pharmacological and non-pharmacological approaches.

Upon completion of the educational program, competence in CVD risk assessment was assessed through an objective structured clinical examination (OSCE) that was offered to all participating pharmacists. The assessment consisted of two stations facilitated by the same trained SPs who participated in the second workshop. In Station 1, competence in performing physical examinations that are necessary for assessing CVD risk factors was evaluated. In Station 2, participants interacted with an SP and gathered relevant information for estimating the SP's absolute CVD risk. At this station, participants also explained to the SP the meaning of the estimated CVD risk in lay language, and drafted an outline for lifestyle changes or pharmacological interventions necessary to address the SP's CVD risk. The participant's skills in this station were assessed using the same checklist that was used in our previous study ${ }^{14}$ which evaluated 3 competencies: CVD risk assessment, CVD risk management, and participant's engagement with the SP. A passing mark for the OSCE was set at $\geq 65 \%$. Thirty percent of the passing mark was derived from the participant's performance in Station 1, and $70 \%$ from the participant's performance in Station 2. The OSCE checklist for stations 1 and 2 are included as Appendix 4 and $\underline{5}$, respectively.

\section{Satisfaction}

A survey to assess the participants' satisfaction and perceived effectiveness of the educational program was 
administered at the end of the educational program. Based on literature review, a 5-point Likert scale ranging from "Definitely yes", "Some", "Not sure", "Not quite" to "Definitely not" was used to evaluate the level of satisfaction. ${ }^{28,29}$ For those who accepted to take part in the OSCE, a list of open-ended questions was given at the end asking them to reflect on various aspects of the educational program provided, about their OSCE experience, what they felt about doing things differently at their practice sites, and which steps they felt they were more prepared to take on the basis of what they had learnt through their participation in this educational program.

\section{Data Analyses}

Data were entered into SPSS ${ }^{\circledR}$ v.22 (IBM, New York, USA) to perform descriptive and inferential analyses. The One-Sample-Kolmogorov-Smirnov test determined that the data was "not normally" distributed. Therefore, descriptive statistics are expressed as median and interquartile range (IQR), and frequencies are expressed as number (n) and percentage (\%) to present the results from pre- and post-questionnaires and from the satisfaction survey, as appropriate. Statistical significance of knowledge data before and after the educational program presented in Tables 1 and 2 were compared using the Wilcoxon signed-rank test and the McNemar Chi-square test, respectively.

\section{Ethical Compliance}

Ethics approval for conducting this study was received from Qatar University Institutional Review Board (QUIRB) in November 2016 (reference number: QU-IRB 672EA/16). The study was carried out in accordance with the principles of the Declaration of Helsinki. The confidentiality of participating pharmacists is maintained. Consent to publish was obtained from the pharmacists as indicated in the participant sheet and consent form.

Table I Evaluation of Participants' Knowledge in CVDRAM

\begin{tabular}{|c|c|c|c|}
\hline & $\begin{array}{l}\text { Before }\left(n=23^{\dagger}\right) \\
\text { Median }(I Q R)\end{array}$ & $\begin{array}{l}\text { After }\left(n=23^{\dagger}\right) \\
\text { Median (IQR) }\end{array}$ & P-value \\
\hline $\begin{array}{l}\text { Knowledge } \\
\text { score out of } 20\end{array}$ & $9(7-10)$ & $12(12-13)$ & $<0.001$ \\
\hline
\end{tabular}

Notes: ${ }^{\dagger}$ Analyses were performed for 23 pharmacists out of 25 since two of them did not complete the post-training questionnaire. Knowledge score is the score obtained on the written pre- and post-questionnaires that are 20 in number including multiple choice questions and true/false type questions given in Table 3 . Abbreviations: IQR, Interquartile range; $n$, number of pharmacists.

\section{Results}

Out of the fifty pharmacists who participated in our previous study, ${ }^{14} 50 \%(\mathrm{n}=25)$ successfully completed the educational program, of which 8 agreed to be evaluated through the OSCE (32\% of participants who enrolled in the educational program).

\section{Impact of the Educational Program on Pharmacists' Knowledge and Skills}

The knowledge and skills of participating pharmacists on CVDRAM improved significantly after participation in the educational program (Table 1). Out of a maximum of 20 , their knowledge scores improved from 9 (7-10) to 12 (12-13) [median (interquartile range)], $\mathrm{p}<0.001$. Table 2 shows the number of pharmacists who had correct responses to knowledge-based questions on the pre- and post-questionnaires. As shown in this table, the number of participating pharmacists answering each of the questions correctly at post-educational program were significantly higher than that at pre-educational program, except for questions $1(\mathrm{p}<1.000), 2(\mathrm{p}<1.000)$ and $18(\mathrm{p}<0.022)$.

All pharmacists achieved a passing score in physical examination and clinical decision making skills by obtaining a passing mark in the OSCE $(\geq 65 \%)$. The median (interquartile range) score for Station 1 was 66 (63-71) out of 100 . The median score for Station 2 was 71 (67-76) out of 100. The highest scores were 74 and 80 for Stations 1 and 2, respectively. To determine whether a participating pharmacist passed the OSCE, 30\% weightage was given to scores from Station 1 and 70\% weightage to scores from Station 2 to arrive at an aggregate of $65 \%$ minimum passing score.

\section{Participant's Perception of the Educational Program}

As illustrated in Figure 2, the majority of participants indicated to be either satisfied or very satisfied with the educational program. Percentage of pharmacists rating the individual items of the satisfaction survey are shown in Table 3. Participants who were evaluated through OSCE reflected positively on their experience. Some of the comments provided are outlined in Table 4.

\section{Discussion}

To the best of our knowledge, our study is novel in that this educational program in CVDRAM was designed systematically after obtaining pharmacists' perceptions, ${ }^{14}$ baseline knowledge and skills and is the first of its kind 
Table 2 Responses to Knowledge Questions in Pre- and Post-Education Questionnaire

\begin{tabular}{|c|c|c|c|c|}
\hline No & Questions & $\begin{array}{l}\text { Pre- } \\
\text { Education, } \\
\text { n (\%) }\end{array}$ & $\begin{array}{l}\text { Post- } \\
\text { Education, } \\
\text { n (\%) }\end{array}$ & P-value \\
\hline I & $\begin{array}{l}\text { MCQ: In adults } 40-79 \text { years of age who are free from atherosclerotic cardiovascular disease } \\
\text { (ASCVD), how often is it reasonable to estimate 10-year ASCVD risk? }\end{array}$ & $6(26)$ & $5(21.7)$ & 1.000 \\
\hline 2 & $\begin{array}{l}\text { MCQ: Which of the following is a general characteristic of the } 2013 \text { ACC/AHA guidelines } \\
\text { that is different than previous guidelines? }\end{array}$ & $3(13)$ & $2(8.7)$ & 1.000 \\
\hline 3 & $\begin{array}{l}\text { MCQ: The following are validated tools for estimating an individual's risk for developing } \\
\text { clinically evident CVD, EXCEPT: }\end{array}$ & $8(34.8)$ & $12(52.8)$ & 0.344 \\
\hline 4 & MCQ: Which of the following measures is needed for estimating CVD risk? & $6(26)$ & $12(52.8)$ & 0.146 \\
\hline 5 & MCQ: All of the following conditions should be recorded when assessing CVD risk, EXCEPT: & $14(61)$ & $23(100)$ & 0.004 \\
\hline 6 & $\begin{array}{l}\text { MCQ: Men at age of } 40 \text { and women at age of } 50 \text { should be offered CVD risk assessment if } \\
\text { they have the following medical history, EXCEPT: }\end{array}$ & II (47.8) & $20(87)$ & 0.012 \\
\hline 7 & $\begin{array}{l}\text { MCQ: Which of the following statements is INCORRECT in regards to the use of antiplatelet } \\
\text { therapy in primary prevention of CVD? }\end{array}$ & $5(21.7)$ & $15(65.2)$ & 0.013 \\
\hline 8 & $\begin{array}{l}\text { MCQ: Which of the following individuals are NOT suitable for starting HMG-CoA reductase } \\
\text { inhibitors (statin) therapy for primary prevention of CVD? }\end{array}$ & $8(34.8)$ & $16(70)$ & 0.021 \\
\hline 9 & $\begin{array}{l}\text { MCQ: Which of the following statin regimens is defined as high-intensity by the ACC/AHA } \\
\text { guidelines? }\end{array}$ & $8(34.8)$ & $22(95.7)$ & 0.000 \\
\hline 10 & $\begin{array}{l}\text { MCQ: Which of the following statements is INCORRECT in regards to obesity management } \\
\text { for patients at risk of developing CVD? }\end{array}$ & $8(34.8)$ & $12(52.8)$ & 0.344 \\
\hline 11 & $\begin{array}{l}\text { MCQ based on a provided case: Which of the following CVD risk reduction strategies is the } \\
\text { MOST suitable for Jane? }\end{array}$ & $9(39.1)$ & II (47.8) & 0.754 \\
\hline 12 & $\begin{array}{l}\text { MCQ based on a provided case: Which of the following lifestyle management strategies are } \\
\text { NOT suitable for Jane? }\end{array}$ & I (4.3) & $9(39.1)$ & 0.008 \\
\hline 13 & $\begin{array}{l}\text { MCQ based on a provided case: What other measurements and follow-up plan is } \\
\text { recommended for Jane? }\end{array}$ & I (4.3) & $5(21.7)$ & 0.219 \\
\hline 14 & $\begin{array}{l}\text { T/F: High-intensity statin therapy generally results in an average LDL-C reduction of } \geq 50 \% \\
\text { from the untreated baseline. }\end{array}$ & $14(61)$ & $23(100)$ & 0.004 \\
\hline 15 & $\begin{array}{l}\mathrm{T} / \mathrm{F}: \text { Sex and race/ethnicity are important risk factors for estimating the } 10 \text {-year risk of a first } \\
\mathrm{CV} \text { event in CVD-free populations. }\end{array}$ & $19(82.6)$ & 22 (95.7) & 0.375 \\
\hline 16 & $\begin{array}{l}\text { T/F: Dietary Approaches to Stop Hypertension diet (aka DASH diet) is one of the } \\
\text { recommended patterns that helps in reducing blood pressure and lipids. }\end{array}$ & $19(82.6)$ & 21 (91.3) & 0.688 \\
\hline 17 & $\begin{array}{l}T / F: \text { In the routine prevention of ASCVD, non-statin therapies provide similar risk-reduction } \\
\text { benefits compared to statin therapy. }\end{array}$ & $14(61)$ & I8 (78.3) & 0.344 \\
\hline 18 & $\begin{array}{l}\text { T/F: } \beta \text {-blockers do not reduce } C V \text { events to the extent that has been proven with thiazide- } \\
\text { type diuretics, } A C E \text { inhibitors, } A R B s, C C B s \text {, or thiazide diuretics. }\end{array}$ & $14(61)$ & $5(21.7)$ & 0.022 \\
\hline 19 & $\begin{array}{l}\text { T/F: Women with polycystic ovary syndrome at age of } 45 \text { years are not candidates for CVD } \\
\text { risk assessment. }\end{array}$ & $14(6 \mathrm{I})$ & $16(70)$ & 0.754 \\
\hline 20 & $\begin{array}{l}\text { T/F: It is irrelevant to estimate the risk of CVD in a patient at age of } 33 \text { who has a low HDL-C } \\
\text { level of }<27 \mathrm{mg} / \mathrm{dL}(0.7 \mathrm{mmol} / \mathrm{L}) \text {. }\end{array}$ & I3 (56.5) & $10(43.5)$ & 0.508 \\
\hline
\end{tabular}

Notes: Analyses were performed for 23 pharmacists out of 25 since two of them did not complete the post-training questionnaire. $\mathrm{n}$ and $\%$ represent the number and percentage of pharmacists, respectively, that answered each question correctly.

to be delivered in Qatar. The study describes in detail the development of an educational program and its impact on the knowledge and skills of practicing community pharmacists to facilitate the provision of CVDRAM services. Moreover, the knowledge and clinical skills were evaluated using both written and OSCE formats.

Our CVDRAM course comprised a blended learning strategy that included direct instructions, self-study materials and multiple active learning components such as face-to-face interactive workshops that provided participants with the opportunity to familiarize with point of care (POC) devices and practice their physical assessment skills using SPs. To the best of our knowledge, this is the first study to include several learning strategies in a single educational program designed to train pharmacists on CVD risk assessment. Workshops, ${ }^{30,31}$ simulation-based 


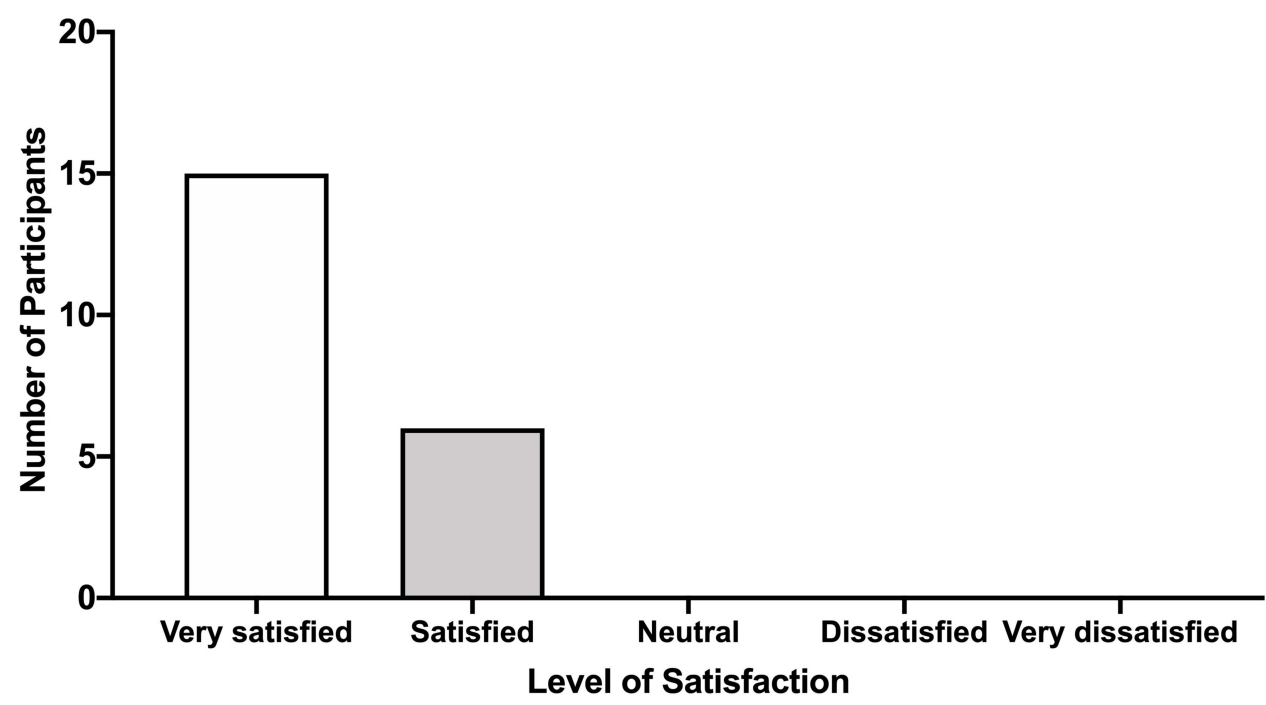

Figure 2 Participants' satisfaction with the educational program. Participants were administered a satisfaction survey at the conclusion of the educational program that was graded on a 5-point scale (very satisfied, satisfied, neutral, dissatisfied and very dissatisfied). The height of the bars represents the number of respondents providing a given rating.

training, ${ }^{32}$ direct instruction, ${ }^{33}$ use of $\mathrm{SPs}^{34,35}$ have been shown to improve knowledge and skills of pharmacists $^{34,35}$ and students ${ }^{36}$ alike. The interaction with trained SPs during the workshops and the continuous availability of the workshop recordings incorporated into the online course provided participants with the opportunity to improve their communication skills and reduce their apprehension when delivering patient education on CVD risk and its management. Similar results were obtained in a study which assessed the learning outcomes when using a blended learning design to deliver a communication course to pharmacy students. ${ }^{37}$ Lastly, the study materials were made available throughout the educational program using Articulate $360^{\circledR}$ and supported the information delivered during the workshops. All of the components of the educational program were in line with advantages of blended learning courses previously described. ${ }^{38}$ Other authors have also reported on the successful use of earlier versions of this Articulate $360^{\circledR}$ webbased software in pharmacy education. ${ }^{39,40}$

The educational program was particularly effective in improving pharmacists' knowledge on a number of

Table 3 Pharmacists' Rating of the Individual Items on the Satisfaction Survey

\begin{tabular}{|c|c|c|c|c|c|}
\hline Statements & $\begin{array}{l}\text { Definitely } \\
\text { Yes }\end{array}$ & Some & $\begin{array}{l}\text { Not } \\
\text { Sure }\end{array}$ & $\begin{array}{l}\text { Not } \\
\text { Quite }\end{array}$ & $\begin{array}{l}\text { Definitely } \\
\text { Not }\end{array}$ \\
\hline Total $n=23$ & & & n (\%) & & \\
\hline Objectives of the training program were clearly defined and met & $22(95.6)$ & $0(0)$ & $0(0)$ & $0(0)$ & $0(0)$ \\
\hline Content of the training were relevant to my practice & $20(86.9)$ & $2(8.6)$ & $0(0)$ & $0(0)$ & $0(0)$ \\
\hline The training content was organized and easy to follow & $20(86.9)$ & $2(8.6)$ & $0(0)$ & $0(0)$ & $0(0)$ \\
\hline On-line content was easy to use & $20(86.9)$ & I (4.3) & I (4.3) & $0(0)$ & $0(0)$ \\
\hline On-line content was understandable & $18(78.3)$ & $2(8.6)$ & $0(0)$ & I (4.3) & $0(0)$ \\
\hline Time allocated for the training program was realistic and sufficient & $20(86.9)$ & I (4.3) & I (4.3) & $0(0)$ & $0(0)$ \\
\hline $\begin{array}{l}\text { The educational program improved my knowledge about CVD prevention } \\
\text { strategies }\end{array}$ & $19(82.6)$ & $2(8.6)$ & I (4.3) & $0(0)$ & $0(0)$ \\
\hline Hands-on training at the professional skills laboratory improved my skills & $19(82.6)$ & $3(13)$ & $0(0)$ & $0(0)$ & $0(0)$ \\
\hline Lecturers are knowledgeable on CVD risk assessment and management & $20(86.9)$ & I (4.3) & $0(0)$ & $0(0)$ & $0(0)$ \\
\hline Lecturers communicated information clearly & $21(91.3)$ & I (4.3) & $0(0)$ & $0(0)$ & $0(0)$ \\
\hline $\begin{array}{l}\text { The educational program has motivated me to participate in Phase } 3 \text { of the } \\
\text { study }\end{array}$ & 21 (9l.3) & I (4.3) & $0(0)$ & $0(0)$ & $0(0)$ \\
\hline
\end{tabular}

Notes: A total of 23 pharmacists completed the satisfaction survey. $\mathrm{n}$ and \% represent the number and percentage of pharmacists, respectively, that gave a specific response to each of the statements. 
Table 4 Participants' Selected Reflections on the Educational Program

\begin{tabular}{|l|l|}
\hline Reflections On & Selected Comments ${ }^{\dagger}$ \\
\hline OSCE & $\begin{array}{l}\text { "OSCE experience was great, we need } \\
\text { more practice to reach the ideal [practice]" } \\
\text { (Participant I) } \\
\text { "OSCE was so much enlightening and } \\
\text { [relaxed]" (Participant 2) }\end{array}$ \\
\hline Educational program & $\begin{array}{l}\text { "There was no bad thing [with the training } \\
\text { course] except that we need more } \\
\text { examples and more practice to confirm } \\
\text { what we have [learnt] but it was really an } \\
\text { amazing experience" (Participant 3) }\end{array}$ \\
\hline Application in practice & $\begin{array}{l}\text { "I have better information now ... and for } \\
\text { sure my whole daily work will get better" } \\
\text { (Participant 2) } \\
\text { "I am going to apply what I have learned" } \\
\text { (Participant 3) }\end{array}$ \\
\hline
\end{tabular}

Note: ${ }^{\dagger}$ Reflections provided by only those who participated in the OSCE.

concepts about CVDRAM, such as the management of dyslipidemia and blood pressure control. This improved knowledge may provide pharmacists with increased confidence to engage with patients for managing these important risk factors. A study on the provision of pharmaceutical care by community pharmacists reported improved adherence to statin therapy with positive clinical outcomes ${ }^{41}$ and on their counselling on lifestyle changes and DASH diet helped patients lower their blood pressure. ${ }^{42}$ Two of the three questions for which wrong responses prevailed in the post-questionnaire (specifically questions 1 and 2) were related to the CVDRAM guidelines. We speculate that the participants did not give much importance to this content. Studies have shown that healthcare providers are generally unaware of guidelines. ${ }^{43}$ Complexity of guidelines, lack of resources and time are other possible reasons why healthcare providers are not using guidelines. ${ }^{44}$ Our future educational programs will emphasize on guidelines and screening criteria for apparently healthy adults that would be translated into practice.

Despite the fact that all participants passed the OCSE, a low score was noted in the physical examination Station 1. This can be explained by two aspects. First, participants may be reluctant to learn and apply physical assessment skills in a community setting where the use of POC devices is not fully supported by Qatar Ministry of Public Health. Second, time to practice physical assessment skills during the workshops could have been insufficient. Thus, reassessing the course delivery for additional practice sessions or increased time for practice is needed to improve participant performance in the future. Compared to our previous study in which participating pharmacists averaged a score of $38 \%$, participants performed well in the post-educational assessment. This could be due to lack of sufficient knowledge as well as unaware of being assessed during their community pharmacy practice work hours where they could have been busy with a series of customers and patients.

The educational program has also been positively evaluated by participating pharmacists, some of whom reported reflections indicative of them being likely to implement what was learnt into their practice settings. This is consistent with findings in similar studies which utilized courses with a blended-learning design to which participants reported positive learning experiences and high satisfaction ratings. ${ }^{39,45-47}$

Low sample size is a limitation of this study. However, the aim of this study was to describe the educational program and its potential application to pharmacy practice in Qatar and elsewhere. Results of the course assessments are informative and should be taken into consideration when deciding the type of educational strategies that are most suitable to deliver CPD programs to improve competencies of community pharmacists in Qatar. Future iterations of the course must more thoroughly evaluate all 4 levels of the Kirkpatrick's evaluation framework, through administration of in-depth interviews with previous participants, their patients, and their managers.

\section{Conclusions}

Overall, the blended-learning educational program in CVDRAM was well received and successful in improving the knowledge and skills of the participating pharmacists. It represents an important resource and a first step in support of implementing access to CVDRAM services within primary care in Qatar.

\section{Data Sharing Statement}

Data supporting the results reported in the manuscript are currently securely stored in password-protected electronic format but can be obtained from the researchers. The content of the educational module described and evaluated herein is not publicly available and it is considered intellectual property of the researchers. Online access to the module is password protected. Access can be solicited to the researchers. No other data than the one presented herein remain unpublished. 


\section{Ethics and Consent Statement}

Ethics approval for conducting this study was received from Qatar University Institutional Review Board (QUIRB) in November 2016 (reference number: QU-IRB 672EA/16). The study was carried out in accordance with the principles of the Declaration of Helsinki. The confidentiality of participating pharmacists is maintained. Consent to publish was obtained from the pharmacists as indicated in the participant sheet and consent form.

\section{Acknowledgments}

We thank all pharmacists who participated in the CVDRAM educational program and CPD-HP (QU Health) which is accredited by QCHP as a provider of CPD in Qatar for their assistance in accrediting the program.

\section{Funding}

This work was made possible by Qatar University (QU) grants QUUG-CPH-15/16-3 and QUST-CPH-SPR-15/16-15 award ed to Dr. Monica Zolezzi and Dr. Sowndramalingam Sankaralingam respectively. The publication of this article was funded by Qatar National Library.

\section{Disclosure}

The authors report no conflicts of interest in this work.

\section{References}

1. WHO. Cardiovascular diseases. Available from: https://www.who.int/ news-room/fact-sheets/detail/cardiovascular-diseases-(cvds). Accessed February 17, 2019.

2. WHO. Prevention of cardiovascular disease: guidelines for assessment and management of cardiovascular risk. 2007. Available from: http:// www.who.int/cardiovascular diseases/guidelines/PocketGL. ENGLISH.AFR-D-E.rev1.pdf?ua=1. Accessed September 15, 2018.

3. Labarthe DR, Dunbar SB. Global cardiovascular health promotion and disease prevention: 2011 and beyond. Circulation. 2012;125 (21):2667-2676. doi:10.1161/CIRCULATIONAHA.111.087726

4. Grundy SM, Pasternak R, Greenland P, Smith S Jr, Fuster V. Assessment of cardiovascular risk by use of multiple-risk-factor assessment equations: a statement for healthcare professionals from the American Heart Association and the American College of Cardiology. Circulation. 1999;100(13):1481-1492. doi:10.1161/01.CIR.100.13.1481

5. Cardiovascular disease risk assessment for primary prevention: our approach. 2019. Available from: https://www.uptodate.com/contents/ cardiovascular-disease-risk-assessment-for-primary-prevention-ourapproach. Accessed February 10, 2019.

6. Blenkinsopp A, Anderson C, Armstrong M. Systematic review of the effectiveness of community pharmacy-based interventions to reduce risk behaviours and risk factors for coronary heart disease. J Public Health Med. 2003;25(2):144-153. doi:10.1093/pubmed/fdg030

7. Ifeanyi Chiazor E, Evans $M$, van Woerden $H$, Oparah AC. A systematic review of community pharmacists' interventions in reducing major risk factors for cardiovascular disease. Value Health Reg Issues. 2015;7:9-21. doi:10.1016/j.vhri.2015.03.002
8. Machado M, Bajcar J, Guzzo GC, Einarson TR. Sensitivity of patient outcomes to pharmacist interventions. Part II: systematic review and meta-analysis in hypertension management. Ann Pharmacother. 2007;41(11):1770-1781. doi:10.1345/aph.1K311

9. Sinclair HK, Bond CM, Stead LF. Community pharmacy personnel interventions for smoking cessation. Cochrane Database Syst Rev. 2004;(1):CD003698.

10. Tsuyuki RT, Al Hamarneh YN, Jones CA, Hemmelgarn BR. The effectiveness of pharmacist interventions on cardiovascular risk: the multicenter randomized controlled RxEACH trial. J Am Coll Cardiol. 2016;67(24):2846-2854. doi:10.1016/j.jacc.2016.03.528

11. McNamara KP, O'reilly SL, Dunbar JA, et al. A pilot study evaluating multiple risk factor interventions by community pharmacists to prevent cardiovascular disease: the PAART CVD pilot project. Ann Pharmacother. 2012;46(2):183-191. doi:10.1345/aph.1Q572

12. Santschi V, Chiolero A, Burnand B, Colosimo AL, Paradis G. Impact of pharmacist care in the management of cardiovascular disease risk factors: a systematic review and meta-analysis of randomized trials. Arch Intern Med. 2011;171(16):1441-1453. doi:10.1001/archinternmed.2011.399

13. El Hajj MS, Mahfoud ZR, Al Suwaidi J, Alkhiyami D, Alasmar AR. Role of pharmacist in cardiovascular disease-related health promotion and in hypertension and dyslipidemia management: a cross-sectional study in the State of Qatar. J Eval Clin Pract. 2016;22(3):329-340. doi:10.1111/jep.12477

14. Zolezzi M, Abdallah O, Kheir N, Abdelsalam AG. Evaluation of community pharmacists' preparedness for the provision of cardiovascular disease risk assessment and management services: a study with simulated patients. Res Soc Admin Pharm. 2019;15(3):252-259.

15. Fahs IM, Hallit S, Rahal MK, Malaeb DN. The community pharmacist's role in reducing cardiovascular risk factors in lebanon: a longitudinal study. Med Prin Pract. 2018;27(6):508-514. doi:10. $1159 / 000490853$

16. Jahangard-rafsanjani Z, Hakimzadeh N, Sarayani A, et al. A community pharmacy-based cardiovascular risk screening service implemented in Iran. Pharm Pract (Granada). 2017;15(2):919.

17. Anderson TJ, Gregoire J, Pearson GJ, et al. 2016 Canadian Cardiovascular Society guidelines for the management of dyslipidemia for the prevention of cardiovascular disease in the adult. Can $J$ Cardiol. 2016;32(11):1263-1282. doi:10.1016/j.cjca.2016.07.510

18. Goff DC Jr, Lloyd-jones DM, Bennett G, et al. 2013 ACC/AHA guideline on the assessment of cardiovascular risk: a report of the American College of Cardiology/American Heart Association Task Force on Practice Guidelines. Circulation. 2014;129(25 Suppl 2): S49-S73. doi:10.1161/01.cir.0000437741.48606.98

19. Ministry of Public Health (MOPH), Doha Q. Clinical guidelines for the state of Qatar. Atherosclerotic cardiovascular disease risk assessment and management. 2016. Available from: https://www.moph.gov. qa/health-strategies/Documents/Guidelines/Guideline-ASCVD risk assessment and managementv1-1FINAL.pdfMOPH. Accessed September 15, 2018.

20. Zealand. MoHN. Cardiovascular Disease Risk Assessment and Management for Primary Care. Wellington: Ministry of Health; 2018.

21. ASC. 2018. Available from: https://articulate.com/360. Accessed September 15, 2018.

22. Kirkpatrick DL, Kirkpatrick JD. Evaluation of Training Programs: The Four Levels. San Francisco (CA): Berrett-Koehler Publishers; 1994.

23. Agness CF, Huynh D, Brandt N. An introductory pharmacy practice experience based on a medication therapy management service model. Am J Pharm Educ. 2011;75(5):82.

24. Bloom BS. Effects of continuing medical education on improving physician clinical care and patient health: a review of systematic reviews. Int $j$ Technol Assess Health Care. 2005;21(3):380-385.

25. Ebn Ahmady A, Barker M, Fahim M, Dragonetti R, Selby P. Evaluation of web-based continuing professional development courses: aggregate mixed-methods model. JMIR Med Educ. 2017;3 (2):e19. doi:10.2196/mededu.5993 
26. Moore DE Jr, Green JS, Gallis HA. Achieving desired results and improved outcomes: integrating planning and assessment throughout learning activities. J Contin Educ Health Prof. 2009;29(1):1-15. doi:10.1002/chp.20001

27. Wilbur K, Shabana S, Maraghi F, ElMubark A, Kheir N. An evaluation of the translation of continuing education into diabetes public health care by pharmacists. Int J Clin Pharm. 2017;39(4):774-782. doi:10.1007/s11096-017-0477-8

28. Abdulghani HM, Shaik SA, Khamis N, et al. Research methodology workshops evaluation using the Kirkpatrick's model: translating theory into practice. Med Teach. 2014;36(Suppl 1):S24-S29. doi:10.310 9/0142159X.2014.886012

29. Gheewala PA, Peterson GM, Zaidi ST, Bereznicki L, Jose MD, Castelino RL. A web-based training program to support chronic kidney disease screening by community pharmacists. Int $J$ Clin Pharm. 2016;38(5):1080-1086. doi:10.1007/s11096-016-0330-5

30. Keller DR, O'dell DV, Skochelak SE, Cochran GL, Shull SJ, Gjerde CJ. Teaching the basics of clinical pharmaceutical care: innovative pharmacy workshops at the University of Wisconsin and the University of Nebraska. Fam Med. 2004;36(Suppl):S89-S92.

31. Mehra IV, Wuller CA. Evaluation of a pilot clinical skills workshop series for community pharmacists. Am J Pharm Educ. 1998;62:136-141.

32. Crea KA. Practice skill development through the use of human patient simulation. Am J Pharm Educ. 2011;75(9):188. doi:10.5688/ ajpe 759188

33. Fakeye TO, Adisa R, Erhun WO. Developing a model for teaching and learning clinical pharmacy components of the pharmacy curriculum in Nigeria. Pharm Educ. 2017;17:60-66.

34. Garcia Corpas JP, Ocana Arenas A, Gonzalez Garcia L, et al. Changes in knowledge after attending a community pharmacists' asthma workshop. Pharm Pract (Granada). 2006;4(3):139-142.

35. Nguyen TS, Nguyen TLH, Van Pham TT, Hua S, Ngo QC, Li SC. Pharmacists' training to improve inhaler technique of patients with COPD in Vietnam. Int $J$ Chron Obstruct Pulmon Dis. 2018;13:1863-1872. doi:10.2147/COPD.S163826

36. Bolesta S, Trombetta DP, Longyhore DS. Pharmacist instruction of physical assessment for pharmacy students. Am J Pharm Educ. 2011;75(2):29. doi:10.5688/ajpe75229
37. Hess R, Hagemeier NE, Blackwelder R, Rose D, Ansari N, Branham T. Teaching communication skills to medical and pharmacy students through a blended learning course. Am J Pharm Educ. 2016;80(4):64. doi:10.5688/ajpe80464

38. Garrison DR, Kanuka H. Blended learning: uncovering its transformative potential in higher education. Internet High Educ. 2004;7 (2):95-105. doi:10.1016/j.iheduc.2004.02.001

39. Crouch MA. An advanced cardiovascular pharmacotherapy course blending online and face-to-face instruction. Am J Pharm Educ. 2009;73(3):51. doi:10.5688/aj730351

40. Tangiisuran B, Tye SC, Tan KW. Implementation and assessment of flipped classroom learning on medication distribution system to pharmacy undergraduates. Pharm Educ. 2017;17(1):109-114.

41. Vegter S, Oosterhof P, van Boven JF, Stuurman-bieze AG, Hiddink EG, Postma MJ. Improving adherence to lipid-lowering therapy in a community pharmacy intervention program: a cost-effectiveness analysis. J Manage Care Spec Pharm. 2014;20(7):722-732. doi:10.18553/jmcp.2014.20.7.722

42. Cheema E, Sutcliffe P, Singer DR. The impact of interventions by pharmacists in community pharmacies on control of hypertension: a systematic review and meta-analysis of randomized controlled trials. Br J Clin Pharmacol. 2014;78(6):1238-1247. doi:10.1111/bcp.12452

43. Zeng L, Li Y, Zhang L, et al. Guideline use behaviours and needs of primary care practitioners in China: a cross-sectional survey. BMJ Open. 2017;7(9):e015379. doi:10.1136/bmjopen-2016-015379

44. Rauh S, Arnold D, Braga S, et al. Challenge of implementing clinical practice guidelines. Getting ESMO's guidelines even closer to the bedside: introducing the ESMO Practising Oncologists' checklists and knowledge and practice questions. ESMO Open. 2018;3(5): e000385. doi:10.1136/esmoopen-2018-000385

45. Carbonaro M, King S, Taylor E, Satzinger F, Snart F, Drummond J. Integration of e-learning technologies in an interprofessional health science course. Med Teach. 2008;30(1):25-33. doi:10.1080/01421590701753450

46. Pahinis K, Stokes CW, Walsh TF, Cannavina G. Evaluating a blended-learning course taught to different groups of learners in a dental school. J Dent Educ. 2007;71(2):269-278.

47. Shaw T, Long A, Chopra S, Kerfoot BP. Impact on clinical behavior of face-to-face continuing medical education blended with online spaced education: a randomized controlled trial. J Contin Educ Health Prof. 2011;31(2):103-108. doi:10.1002/chp.20113
Risk Management and Healthcare Policy

\section{Publish your work in this journal}

Risk Management and Healthcare Policy is an international, peerreviewed, open access journal focusing on all aspects of public health, policy, and preventative measures to promote good health and improve morbidity and mortality in the population. The journal welcomes submitted papers covering original research, basic science, clinical \& epidemiological studies, reviews and evaluations, guidelines, expert opinion and commentary, case reports and extended reports. The manuscript management system is completely online and includes a very quick and fair peer-review system, which is all easy to use. Visit http://www.dovepress.com/testimonials.php to read real quotes from published authors. 